\title{
Using Hybrid Power Generation to Ensure the Reliability of Power System in Jordan
}

\author{
Ahmad Bataineh \\ Electrical and Electronics Eng. Dept, Al-Huson University College, \\ Al-Balq'a Applied University, Irbid 21510, Jordan \\ Anwar Al-Mofleh* \\ Electrical Engineering Department, Faculty of Engineering Technology, \\ Al-Balqa' Applied University, Amman 11134, Jordan
}

\begin{abstract}
There is an increase in the growing of interest in renewable energy system, especially solar and wind for their availability and cost of running competition in the Middle East. Hybrid systems of renewable energy generation have two or more different sources usually generate different types of ensuring the continuous supply of electrical charges. The system is considered to consist of wind turbines, batteries, optical, and conventional diesel generators to power a variable load at a speed of $62 \mathrm{kWh} /$ day with the peak load of $6 \mathrm{~kW}$, peak load. The study was based on real data on wind speed and solar radiation to Amman city. There are several options available compared to using a software package HOMER Technical and economic view, economic, and possible low of pollutant emissions.
\end{abstract}

Keywords: Hybrid system, Optimal system design , Economy, Environment, HOMER software

DOI: $10.7176 /$ JETP/9-5-04

Publication date:June $30^{\text {th }} 2019$

\section{Introduction}

Jordan is a key country in the Middle East region. Much of its budget is earmarked for the import of oil from several countries. The problem worsens year after year due to population growth and increasing demand for electricity. The search for other sources of energy has become an important issue in Jordan [1, 2 and 3]. Current energy production process in Jordan depends on fossil fuels. Jordan's oil reserves estimate about 1 million barrels, and natural gas reserves estimate at about 200 million cubic feet [4]. Relatively low fossil fuel resources force the country to import most of the fuel needed for electricity generation; 88\% of Jordan's electricity production relies on imported fossil fuels. The import of fossil fuels has proved to be an exhausting economic burden for Jordan, accounting for almost $40 \%$ of the country's budget. [5]. Due to the ever-changing political situation in the Middle East, Jordanian energy security is constantly threatened, as it imports significant quantities of Iraqi oil and natural gas from Egypt through the Arab pipeline (PGA) through Sinai and Syria. In recent years the political instability of Syria and Sinai has led to a dramatic decline in Jordanian gas imports from 89 billion cubic feet to 17 billion cubic feet and effectively caused [6,7]. The deployment of energy systems is their benefits, such as security of supply, reducing carbon emissions and improving energy quality, since renewable energy (RE) resources are of an intermittent nature. The Hybrid Renewable Energy System (HRES) combines two or more renewable energy sources with any conventional source (diesel or gasoline generator) along with storage to meet the demand for an area. An example of the PV-HRES diesel wind generator is shown in Figure 1[8].

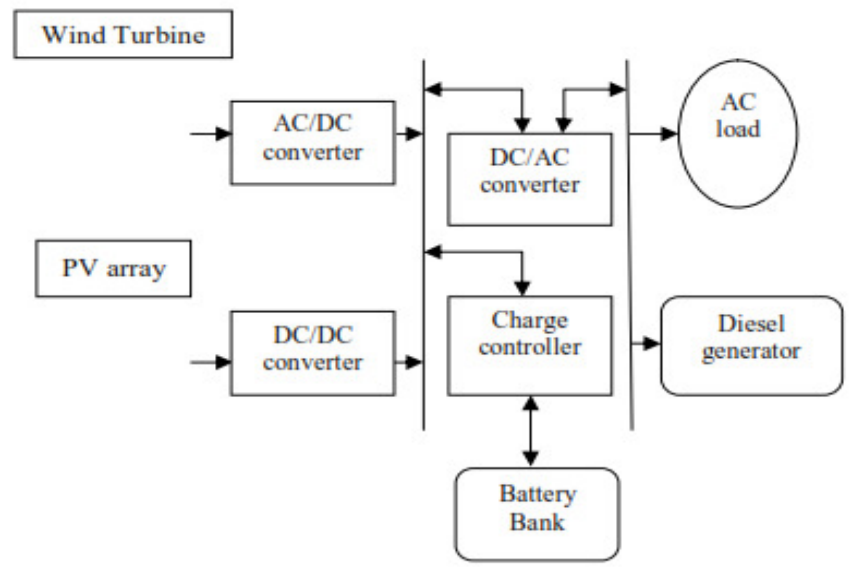

Figure 1. An example of PV-wind diesel generator 


\section{Benefits of Hybrid Systems}

\subsection{Improved reliability}

A robust power supply and minimized downtime during power outages could be achieved under various power sources. The failure of the system or the interruption of the diesel supply to the community is factors that lead to the use of an alternative generation system that covers the hybrid / diesel hybrid system. The photovoltaic and wind power system attributes fewer moving parts, which requires less maintenance than diesel, which reduces downtime during repairs or routine maintenance. In fact, renewable energy sources are indigenous and free is safer than diesel, therefore, beneficial to facilities $[9,10]$.

\subsection{Improved energy services}

The capacity of renewable energies working in parallel with diesel fuel contributes to high quality and dynamic electric services for 24 hours / day, while in a conventional system, high diesel operating costs limit the power supply to only 12 hours / day. The cost of photovoltaic or wind power generation is in the form of capital expenditures in advance, so operating and maintenance costs are low.

\subsection{Reduced emissions and noise pollution}

Diesel generation emits air and water pollution agents as well as loud noises, demonstrating the essentiality of the application of renewable of renewable energy or diesel in the generation of energy that adopts a technology respectful with the environment. In fact, the renewable energy system is also substantially quieter than diesel generators.

\subsection{Increased operational live}

Operation at regular intervals and specific occurrences of renewable energy and diesel hybrids could extend the life of the overall system due to the discontinuous use of the diesel group

\subsection{Efficient use of energy}

Hybrid system promotes efficient use of power from a renewable energy system could be configured to cope with base load whilst the peak load could be met via diesel generator

\section{Proposed Calculation}

The aim of this study is to develop an autonomous hybrid generation system that should be appropriate for economic, reliable and environmental measurements for physical and operational constraints / strategies [11].The system costs are calculated as the sum of PV costs (CPV), WG costs (CWG), battery costs (CBAT), electrolytic costs (CELEC), fixed costs (CF), converter costs (CCONV) and hydrogen tank costs (CTANK).

$$
\mathrm{CSYSTEM}=\mathrm{CPV}+\mathrm{CWG}+\mathrm{CBAT}+\mathrm{CELEC}+\mathrm{CF}+\mathrm{CCONV}+\mathrm{CTANK}
$$

The cost of each element should be deducted:

$$
\mathrm{Ci}=\mathrm{Ni} *[\mathrm{CCosti}+\mathrm{RCosti} * \mathrm{Ki}+\text { O\&MCosti }]
$$

$\mathrm{i}=\mathrm{PV}, \mathrm{WG}$, Battery, FC, Electrolyses, where Ni is the number/size of the system component, CCosti is the capital cost, RCosti is the replacement cost, $\mathrm{Ki}$ is the number of replacements, and O\&MCosti is operation and maintenance cost through the system operation [11-14].

\section{Case Study of A Hybrid System}

To choose the best design suited for the case of operation of the hybrid system, the electrical load needs a proper and detailed study in terms of its nature, amount, pattern, and relationship with time. As one of the important components of the design, it is necessary to determine the amount of load loss allowed as it is one of the important components of the design. To assess the sources and select the most appropriate one it is necessary to collect the data related to each of the sources be available. The capacity of each component of the system and the method of optimal connectivity between components can be determined after an evaluation study is completed. Our study is to secure power supply to electrical loads rated $62 \mathrm{kWh} /$ day with $6 \mathrm{~kW}$ peak load using a hybrid system (wind photovoltaic - batteries - diesel generator). The HOMER software provides us with a number of possible solutions. A comparison is conducted between the various possible solutions and the conventional method to select the solution with minimum cost, and obtained possible low of pollutant emissions in environment.

\subsection{Wind Speed Data}

We considered an official real data for wind speed taken from Meteorological Department of station monitoring for a wind station in Amman Governorate near to the site to be studied. The data is as indicated in Figure 2 below which shows the average monthly wind speed plotted versus time for the period 2012-2016. 


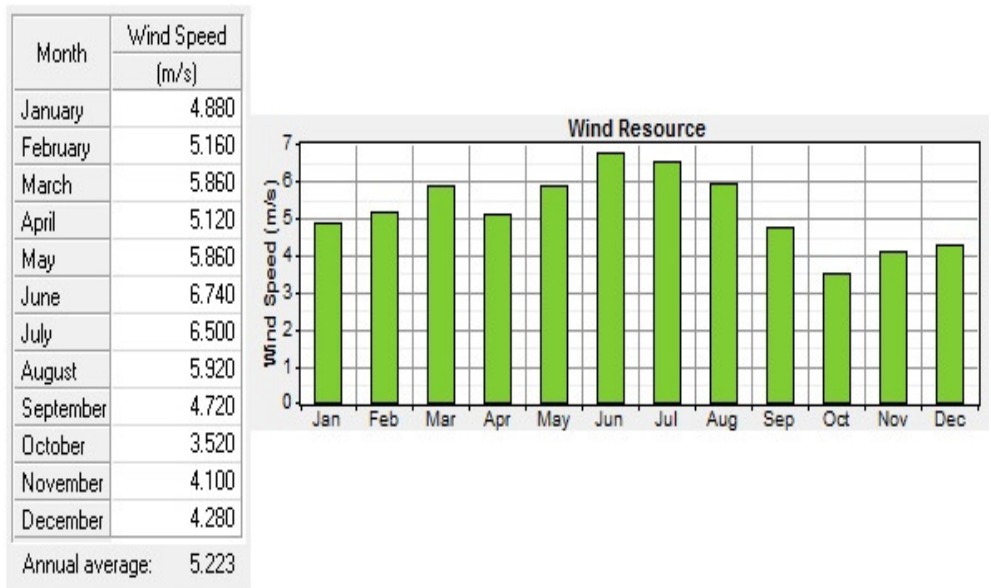

Figure . 2. Average monthly wind speed during the period (2012-2016)

\subsection{Solar Radiation Data}

We considered an official real data for solar radiation intensity taken from the neighboring monitoring station in Amman Governorate which is a part of the National Energy Research Center in Jordan. The data is as indicated in Figure 3 below which shows the daily radiation power density in $\mathrm{kW} / \mathrm{m} 2 /$ day plotted versus time for the period 2012-2016.

\begin{tabular}{|l|c|r|}
\hline \multirow{2}{*}{ Month } & Clearness & Dally Radiation \\
\cline { 2 - 3 } & Index & \multicolumn{1}{c|}{$[\mathbf{k W h} / \mathrm{m} 2 / \mathrm{d})$} \\
\hline January & 0.557 & 3.085 \\
\hline February & 0.566 & 3.861 \\
\hline March & 0.641 & 5.460 \\
\hline April & 0.638 & 6.445 \\
\hline May & 0.695 & 7.726 \\
\hline June & 0.724 & 8.310 \\
\hline July & 0.726 & 8.180 \\
\hline August & 0.711 & 7.430 \\
\hline September & 0.714 & 6.452 \\
\hline October & 0.687 & 5.019 \\
\hline November & 0.624 & 3.627 \\
\hline December & 0.596 & 3.062 \\
\hline Average: & 0.670 & 5.731 \\
\hline
\end{tabular}

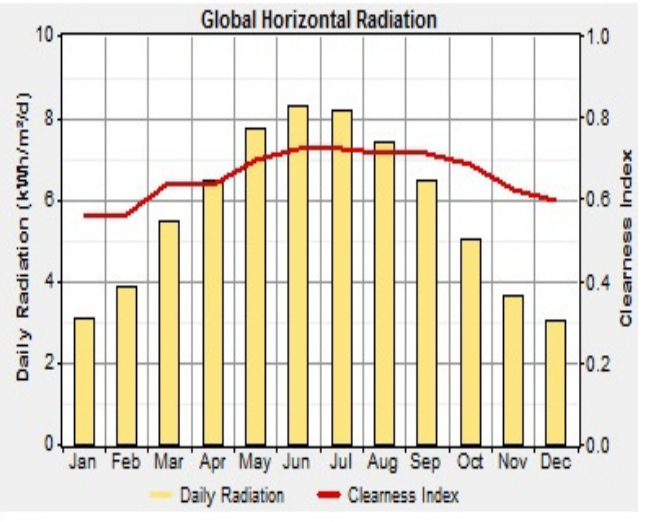

Figure. 3. Average monthly solar radiation density during the period (2012-2016)

\subsection{Electrical Load}

Data for electrical charges at the site are taken from the Amman District Electricity Company (ADECO). The average daily profile of the electric charge (AC) at the study site is shown in Figure 4, which shows the average load in $\mathrm{kW}$ as a function of time in hours. The average daily profile of the AC load at the study site, which varies from month to month, is shown in Figure 5, which shows the average load in $\mathrm{kW}$ as a function of time in hours for certain months.

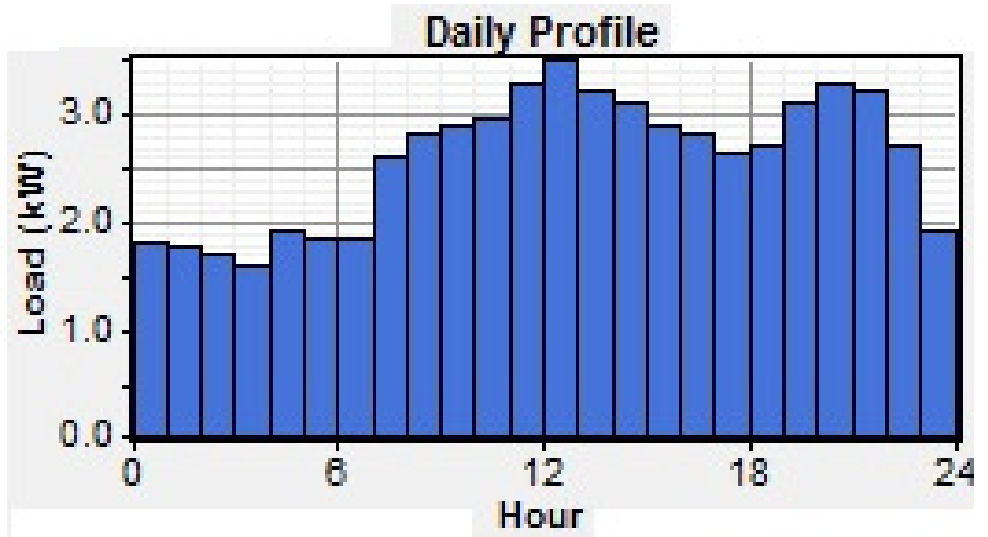

Figure . 4. Daily profile of electrical load 


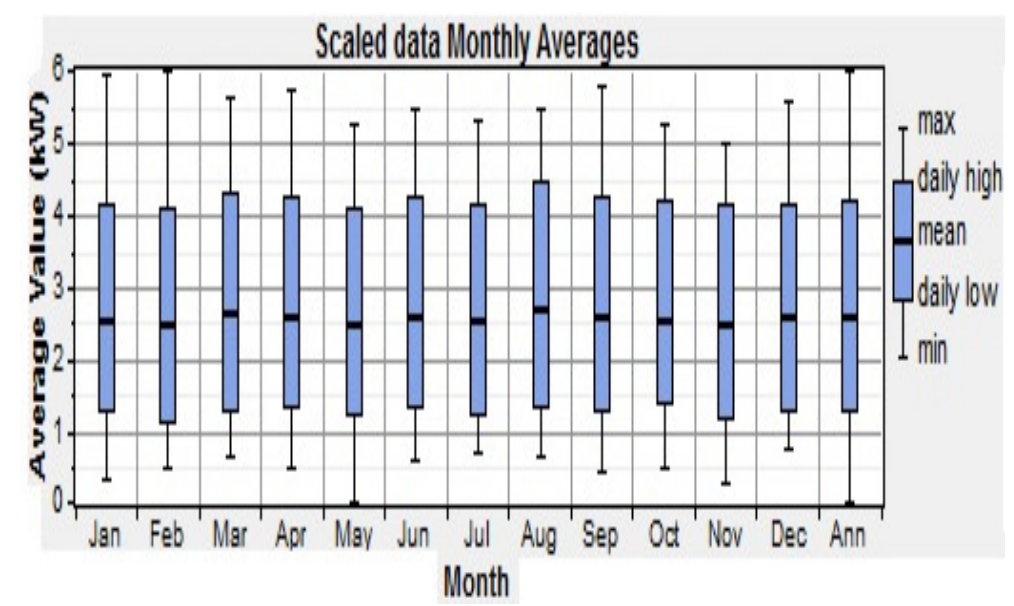

Figure.5. Average load in $\mathrm{kW}$ plotted versus time in hours for all months

The average monthly energy consumption of AC electrical load at the study site as it varies from month to month is as depicted in Figure 6 which shows the average load in $\mathrm{kWh}$ plotted versus months for the period 2012-

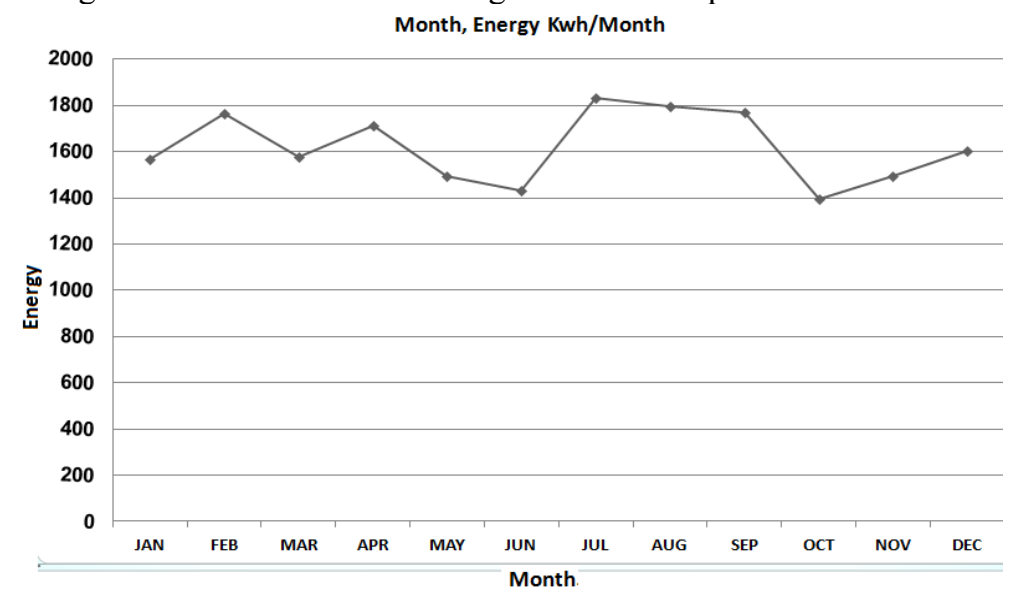

Figure. 6. Average energy consumption versus months during the period (2012-2016)

\subsection{Implementation of the Hybrid System}

The implementation and optimal parameters of the hybrid power generation system are determined using the HOMER software. The proposed system comprises primary renewable sources (wind / PV) which are supported by conventional secondary backup sources (generator / diesel batteries). The power converter is included in the system to connect between AC and DC links and the control unit. The HOMER software is also used for the study of system prefeasibility, as well as for sensitivity analysis. Figure 8 shows that the components of the proposed hybrid system modeled using the HOMER program are as specified below:

A. Generic $10 \mathrm{KW}$ wind turbine model is used in this system; it has a nominal capacity of $10 \mathrm{~W}$ and provides direct current. The initial cost of capital, replacement and maintenance-operation of a unit is 6000 U.S.D, 4500 U.S.D and 180 U.S.D. / year, respectively. The useful life of a wind turbine is considered to be 15 years. The power curve of the wind turbine generator is shown in Figure 7 and details of the wind resource are shown previously in Figure 2. 


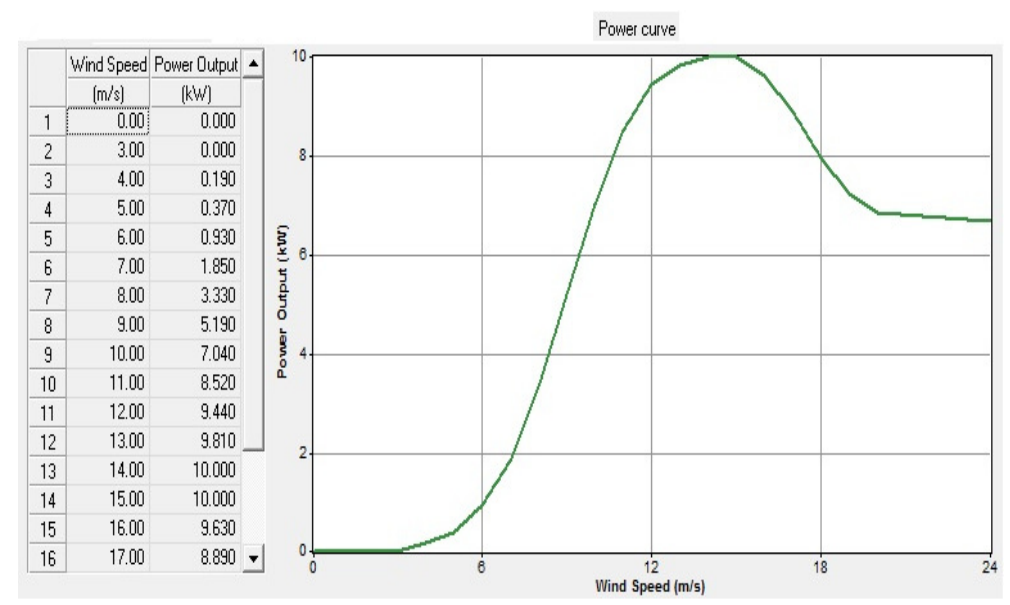

Figure. 7. Power curve of the wind generator

B. Photovoltaic solar modules are flexible and can be connected in series, in parallel or both. When the sun's rays hit the photovoltaic solar panels, it produces electricity. Each module produces $10 \mathrm{~kW}$ of DC power. The solar panels are of the fixed type that does not follow the direction of the sun. The initial costs of capital, replacement and operation-maintenance are 12500 U.S.D, 12225U.S.D and 280 U.S.D. / year, respectively. The lifetime of a PV is 20 years and details of the solar radiation resource are shown in Figure 2.

C. The Diesel generator is of the conventional type with capacity $10 \mathrm{~kW}$ and loading rate youngest $30 \%$. The limit fuel consumption is $5 \mathrm{~m} 3$ per year and the price of liter is 0.7 U.S.D. The initial capital, replacement, and operation-maintenance cost are 5000 U.S.D, 4500 U.S.D and 5 U.S.D/hr respectively. The expected lifetime of a diesel generator is 15000 hour.

D. The batteries are Hoppecke $12 \mathrm{Opzs} 1500$ which has a nominal space $2 \mathrm{~V}, 1500 \mathrm{~A}$, and $3 \mathrm{kWh}$. The lifetime of these batteries is 4 years minimum. The single battery initial capital, replacement, and maintenance-operation cost are 305 U.S.D, 280 U.S.D, and 3.5 U.S.D / year.

E. Power Converter is included in order to maintain the flow of energy between the $\mathrm{AC}$ and the $\mathrm{DC}$ bus. The input efficiency of the DC/AC inverter is $90 \%$ while the input efficiency of the AC/DC rectifier is $85 \%$. The size of the convertor that is used in this system is $10 \mathrm{~kW}$. The initial capital, replacement, and operation-maintenance costs are 3000 U.S.D, 2800 U.S.D and 60 U.S.D / year respectively. The lifetime of the converter is taken to be 15 years

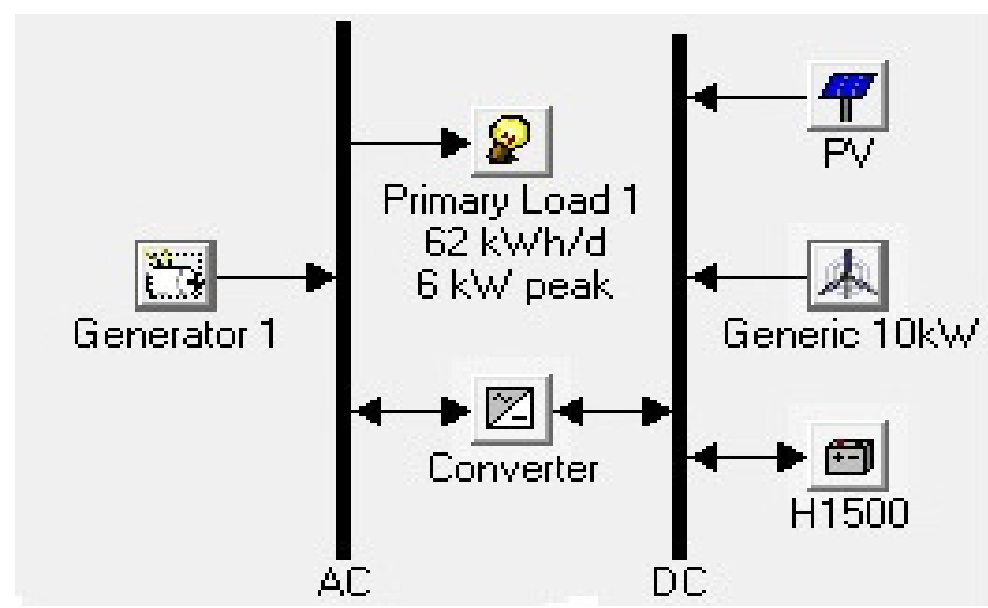

Figure. 8. Hybrid system elements and electrical load connection

\section{Results and Discussion}

Several simulations were performed to obtain the optimum hybrid system and to determine the adequate supply of the electric energy that satisfies the required load demand. Table 1 shows a summary of each variety of the system, including the value of photovoltaic power capacity, wind turbine generator, conventional diesel generator and batteries. Figure 9 shows the monthly average electricity output of the PV and the generator of case 2 mentioned in Table 1. Figure 10 shows the cost detail histogram for the same case. The Simulation Results Emissions pollutant of the hybrid systems (PV \& generator for Case 2), in the System Architecture as shown in Table 2 
Table 1 HOMER summary of optimization results

\begin{tabular}{|l|l|l|l|l|l|l|l|l|l|l|l|l|}
\hline Case & PV(kw & G10 & Label & H1500 & Conv.(kw) & $\begin{array}{l}\text { Initial } \\
\text { Capital \$ }\end{array}$ & $\begin{array}{l}\text { Operating } \\
\text { cost }(\$ / y)\end{array}$ & $\begin{array}{l}\text { Total } \\
\text { NPC }\end{array}$ & $\begin{array}{l}\text { COE } \\
\$ / \text { KWH }\end{array}$ & $\begin{array}{l}\text { Ren. } \\
\text { Frac. }\end{array}$ & $\begin{array}{l}\text { Diesel } \\
\text { L }\end{array}$ & Label \\
\hline 1 & 26 & & & 55 & 10 & 36.025 & 989 & 48.674 & 0.168 & 1.00 & & \\
\hline 2 & 20 & & 10 & 40 & 10 & 32.700 & 1584 & 52.950 & 0.183 & 0.96 & 316 & 98 \\
\hline 3 & 20 & 2 & 10 & 25 & 10 & 40.125 & 1374 & 57.687 & 0.199 & 0.99 & 52 & 18 \\
\hline 4 & 22 & 2 & & 40 & 10 & 40.950 & 1415 & 59.036 & 0.204 & 1.00 & & \\
\hline 5 & & 4 & 10 & 60 & 10 & 50.300 & 3089 & 89.785 & 0.310 & 0.92 & 653 & 195 \\
\hline 6 & & 6 & & 140 & 10 & 81.700 & 2844 & 118.057 & 0.408 & 1.00 & & \\
\hline 7 & & & 10 & 25 & 10 & 15.625 & 23342 & 314.015 & 1.085 & 0.00 & 9.837 & 2.98 \\
\hline
\end{tabular}

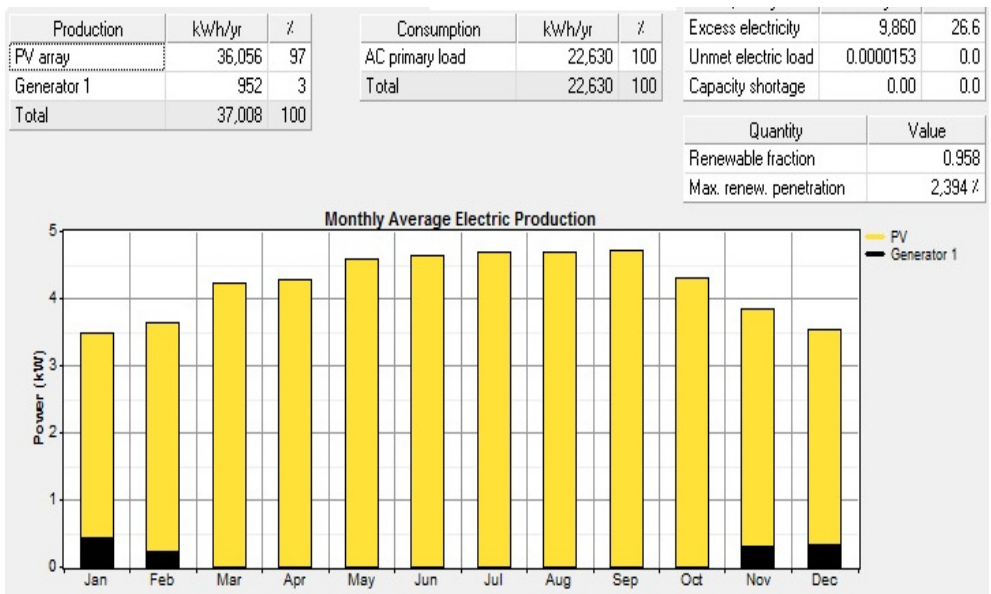

Figure 9. Monthly average electric production (PV \& generator)

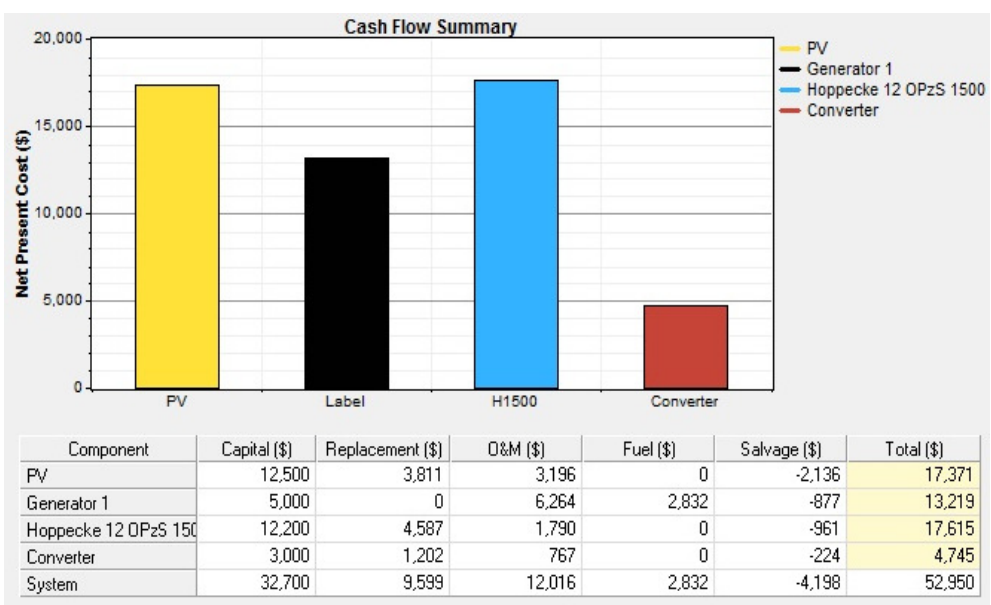

Figure 10. Histogram of cost details (PV \& generator for Case 2)

Table 2. Emissions pollutant of the hybrid systems (PV \& generator

\begin{tabular}{|c|c|}
\hline Pollutant & Emissions $(\mathrm{kg} / \mathrm{yr})$ \\
\hline Carbon dioxide & 833 \\
\hline Carbon monoxide & 2.06 \\
\hline Unburned hydocarbons & 0.228 \\
\hline Particulate matter & 0.155 \\
\hline Surfur dioxide & 1.67 \\
\hline Nitrogen oxides & 18.4 \\
\hline Total & 855.513 \\
\hline
\end{tabular}

The Simulation Results Emissions pollutant of the traditional diesel generation system (Case7), in the System Architecture as shown in Table 3 
Table 3. Emissions pollutant of the traditional diesel generation system (Case7)

\begin{tabular}{|c|c|}
\hline Pollutant & Emissions $(\mathrm{kg} / \mathrm{yr})$ \\
\hline Carbon dioxide & 25903 \\
\hline Carbon monoxide & 63.9 \\
\hline Unburned hydocarbons & 7.08 \\
\hline Particulate matter & 4.82 \\
\hline Surfur dioxide & 52 \\
\hline Nitrogen oxides & 571 \\
\hline Total & 26601,8 \\
\hline
\end{tabular}

The Simulation Results Figure 11 shows System Architecture the monthly average electric production of the generator of case 7, and Figure 12 shows the histogram of the cost detail for the same case mentioned in Table 1

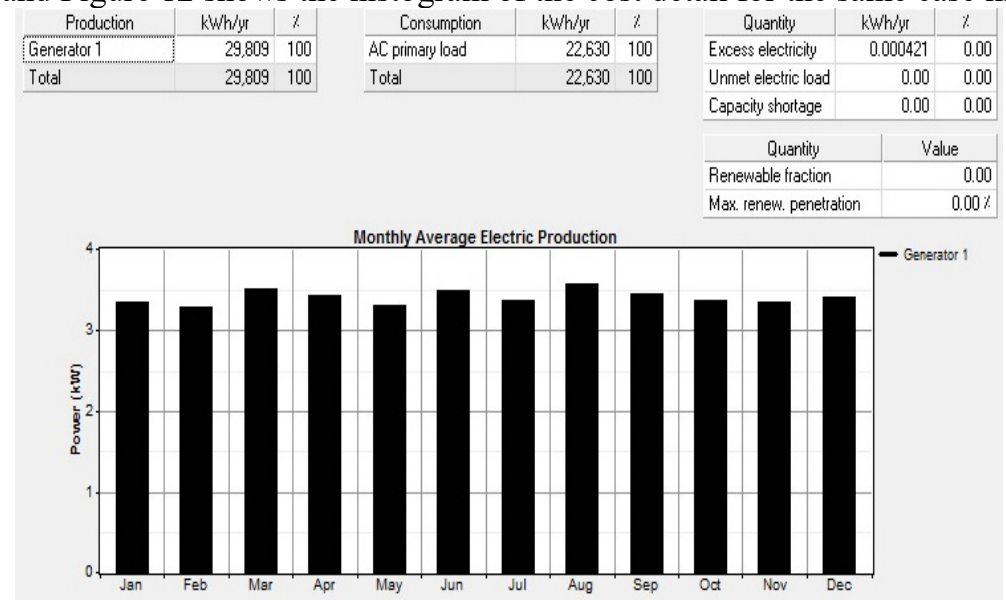

Figure11. Monthly average electric production generator for (Case 7)

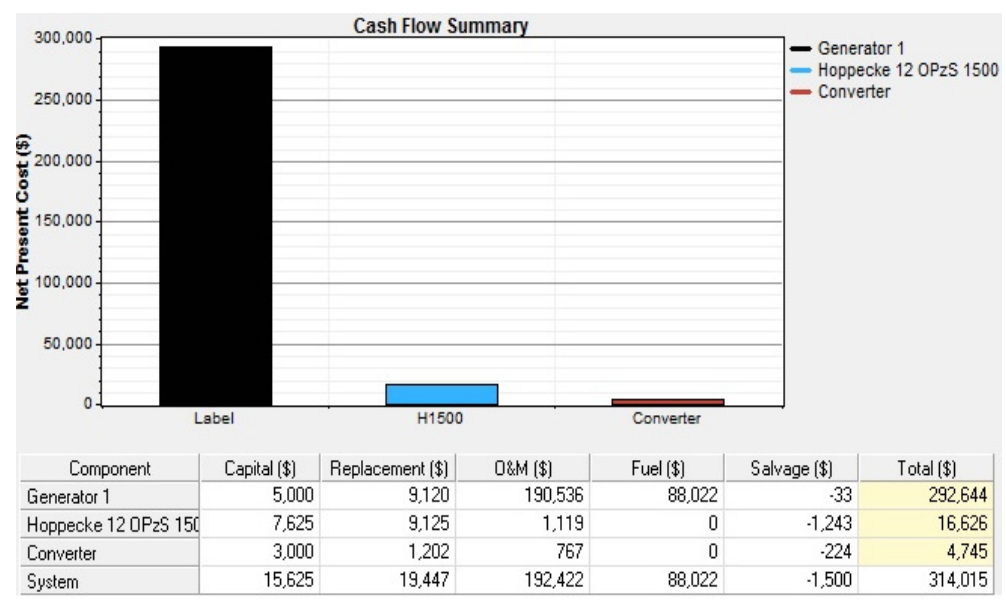

Figure 12. Histogram of cost details (Case 7)

A direct comparison of the results economic feasibility and pollutant emissions of the system configurations described in Table.1-3 shows that:

The hybrid systems labelled as cases 1, 2, 3, and 4 in Table 1 are the best options available to secure the power supply, and more safe Comparing the a conventional diesel generation labeled as case 7 .

- The hybrid systems labelled cases 1 and 2 in Table 1 are chosen as optimal hybrid system design for feeding the electrical loads. It is worth mentioning that case 1 consists of photovoltaic system of capacity $26 \mathrm{~kW}$, batteries of 55, while case 2 consists of photovoltaic system of capacity $20 \mathrm{~kW}$, batteries of 40 , and a 10 $\mathrm{kW}$ conventional diesel generator.

- Comparing the hybrid systems for cases 1, 2 In Table 1 in terms of feeding preference and continuity of electrical power supply, we have chosen case 2 since that net present cost (NPC), and average cost of energy (COE) per $\mathrm{kWh}$ for case 1, 2 are almost equal. The inclusion of conventional diesel generator in the system guarantees its work in very cloudy situations. Moreover, the low capacity and cost of batteries for case 2 (44) compared to that of case 1 (55), and initial capital (IC) from 36,025 U.S.D for case 1 to 32,700 U.S.D for case 2 .

- The average cost value of power per $\mathrm{kWh}$ in Table 1 for the hybrid systems described in case 1 is equal to 
0.168 U.S.D / kWh, case 2 is equal to 0.183 U.S.D / $\mathrm{kWh}$ while the cost of traditional diesel generation system described in case 7 is equal to 1.085 U.S.D / $\mathrm{kWh}$.

- The total pollutant emissions in environment for hybrid systems (PV \& generator) described in case 2 in Table 2. Is equal to $855.513 \mathrm{~kg} / \mathrm{yr}$, while the of traditional diesel generation system described in case 7 in Table 3. Is equal to $26601.8 \mathrm{~kg} / \mathrm{yr}$.

\section{Conclusions}

The comparative results of technical and economic simulation show the importance of hybrid systems that adopt renewable energy sources to ensure the supply of energy to electrical loads in remote areas. Based on the comparative simulation carried out using the HOMER software, the hybrid system labeled case 2 is chosen as the optimum system design. The hybrid system in case 2 is more reliable in terms of power preferences and continuity of the electric power supply as discussed above.

- The study showed a comparative importance between emissions of pollutants in the environment for the safest (PV and generator for case 2) system Comparing the generation of conventional diesel (case 7) to ensure a clean and safe environment that does not represent A threat to Human and animal due to the inhalation of these pollutant emissions

- The study also showed the importance of the addition of a conventional diesel generator to the components of hybrid system, not as an option but to ensure the continuous feeding of the electrical loads in some rare but critical condition especially for remote areas far from electrical grid.

\section{References}

Green Energy DC program (District of Columbia, Washington,DC,USA),http://www.green.dc.gov/green/cwp/view,a,1244,q,461338.asp

Kingdom of Jordan's Ministry of Energy and Mineral Resources (2007), Updated Master Strategy of Energy Sector in Jordan for the period (2007-2020).

The California Solar Initiative program (California, USA),http://www.gosolarcalifornia.ca.gov/csi/index.html. (June, 2014)

T. Key, "Finding a bright spot", IEEE Power and Energy Magazine, vol.7, no.3, pp.34-44, May-June 2009.

Y. Anagreh, A. Bataineh and M. Al- Odat, solar energy potential in Jordan, ICEGES 2009

Renewable Energy and Energy Efficiency Law, Law No. (13) Of 2012. [Online] Available: http

Yousef El-Tous, A Study of a Grid-connected PV Household System in Amman and the Effect of the Incentive Tariff on the Economic Feasibility, International Journal of Applied Science and Technology, Vol. 2 No. 2; February 2012.

Swati Negi and Lini Mathew" Hybrid Renewable Energy System: A Review” International Journal of Electronic and Electrical Engineering. Volume 7, Number 5 (2014), pp. 535-542

Kamaruzzaman Sopian and Mohd Yusof Othman /ISESCO Science and Technology Vision Volume 1 (May 2005) (37-39)

Eliasson. B. (2000) The Road to Renewable: Opportunities and Challenges, World Renewable Energy Congress VI, Brighton, 1 - 7 July, pp 64-68.

Ahmad Bataineh, Amin Alqudah \& Abedalgany Athamneh, Optimal Design of Hybrid Power Generation System to Ensure Reliable Power Supply to the Health Center at Umm Jamal, Mafraq, Jordan, Energy and Environment Research; Vol. 4, No. 3; 2014

Anagreh Y., \& Bataineh, A. (2011). Renewable energy potential assessment in Jordan. Renewable and Sustainable Energy Reviews, 15, 2232-2239. http://dx.doi.org/10.1016/j.rser.2011.02.010

Anagreh Y., \& Al-Ghzawi, A. (2013). Feasibility of utilizing renewable energy systems For a small hotel in Ajloun city, Jordan. Applied Energy, 103, 25-31. http://dx.doi.org/10.1016/j.apenergy.2012.10.008

Anayochukwu, A. V., \& Ndubueze, N. A. (2013). Potentials of Optimized Hybrid System In Powering Off-Grid Macro Base Transmitter Station Site. International Journal of renewable energy research, 3(4), 861-871. 